\title{
Mudanças organizacionais na gestão da escola e sua relação com o mundo empresarial: aprofundamento da privatização na educação básica brasileira?
}

Organizational changes in school management and its relationship with the
business world: deepening of privatization in the Brazilian basic education?

\section{Los cambios organizativos en la gestión escolar y su relación con el mundo de la empresa: la profundización de la privatización en la educación básica brasileña?}

Theresa Maria Freitas Adrião'

Teise de Oliveira Guaranha Garcia"

'Faculdadde Educação - (UNICAMP) SP,Campinas - Brasil - Email theadriao@gmail.com

"Faculdade de Filosofia, ciências e letras (USP) SP - Ribeirão Preto - Brasil - Email teiseg2@gmail.com

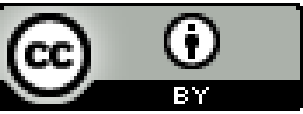

Educação: teoria e prática, Rio Claro, SP, Brasil - eISSN: 1981-8106

Está licenciada sob Licença Creative Common

\section{Resumo}

O artigo aborda transformações na gestão empresarial capitalista nas últimas décadas e sua incidência sobre proposições para a gestão da escola pública. Discutem-se as formas por meio da quais os temas autonomia, participação, avaliação, redução de níveis hierárquicos e trabalho em equipe são apresentados como soluções para gestão educacional e escolar, referenciados nas teorias e tecnologias de gestão voltadas à ampliação do capital. Ao contrário do relevante lugar ocupado por tais temas nas lutas sociais pela democratização da gestão escolar, pretende-se reorganizar o trabalho à semelhança do que se faz na empresa privada. Conclui-se que tais soluções, apresentadas como esforço de generalização da lógica capitalista de gestão no interior da escola, não contribuem para a qualidade da educação pública e para a democratização da gestão escolar, por não considerarem a especificidade do processo de trabalho pedagógico.

Palavras-chave: Gestão escolar. Privatização. Educação básica.

\section{Abstract}

The article discusses changes in the capitalist business management in recent decades and its impact on proposals for the management of public schools. We discuss the ways through which the subjects autonomy, participation, evaluation, reduction of hierarchical levels and teamwork are presented as solutions to educational and school management, referenced in 
management theories and technologies related to the expansion of capital. Unlike the important place occupied by such themes in social struggles for democratization of school management, the aim is to reorganize the work similar to what is done in private company. It follows that such solutions presented as an effort to generalize the capitalist logic of management within the school does not contribute to the quality of public education and the democratization of school management, believing the specificity of the pedagogical work process.

Keywords: School management. Privatizing. Basic education.

\section{Resumen}

El artículo analiza los cambios en la gestión empresarial capitalista en las últimas décadas y su impacto sobre las propuestas para la gestión de las escuelas públicas. Se discuten las formas en que la autonomía de los sujetos, la participación, la evaluación, la reducción de los niveles jerárquicos y el trabajo en equipo se presentan como soluciones a la gestión educativa y la escuela, que se hace referencia en las teorías de gestión y tecnologías relacionadas con la ampliación de capital. A diferencia del importante lugar que ocupa este tipo de temas en las luchas sociales para la democratización de la gestión escolar, el objetivo es reorganizar el trabajo similar a lo que se hace en la empresa privada. De ello se desprende que tales soluciones, presentadas como un esfuerzo por generalizar la lógica capitalista de gestión dentro de la escuela, no contribuyen a la calidad de la educación pública y la democratización de la gestión escolar, ya que no tienen en cuenta la especificidad del proceso de trabajo pedagógico.

Palabras-clave: Gestión escolar. Privatización. Educación básica.

\section{Introdução}

Este texto busca sistematizar reflexões relativas à adoção, na escola pública, de mecanismos, ferramentas e lógica cunhados na e para a gestão empresarial, configurando uma tendência iniciada na década de 1990. A temática tem sido exaustivamente analisada por vários autores, nacionais e internacionais como (PERONI, 2012, 2013; OLIVEIRA, 2014, 2004, 2002, 1997; PARO, 1999, 2012; ADRIÃO; BEZERRA, 2013; ADRIÃO et al., 2009; ADRIÃO, 2009; BRUNO, 1997; FREITAS, 2012; LIMA, 2011; BALL, 2001; BARROSO, 1996, 2005; HILL, 2003 entre outros).

Considera-se que tal transposição, no final do século XX, foi facilitada por mudanças ocorridas no campo da gestão empresarial, as quais, ainda que se disseminem de forma desigual e combinada (TROTSKY, 1977; LOWY, 1998), apoiam-se na defesa de certos elementos que se apresentam constantes, tanto no que se convencionou chamar de modelo japonês, quanto nas tentativas ocidentais de adequação desse modelo (HYPOLITO, 1991; GOUNET, 1999; HARVEY, 2002).

O artigo é organizado em dois itens principais: No primeiro deles Gestão empresarial: cinco aspectos, buscamos sintetizar e caracterizar novos elementos da gestão empresarial que tendem a ser assimilados como alternativas para a qualificação da escola. No segundo item, $A$ gestão empresarial estendida à escola pública: um exercício de reflexão, discute-se a 
transposição dos referidos elementos à educação pública. Finalmente, algumas considerações são apresentadas.

]

\section{Gestão empresarial: cinco aspectos}

Como forma de orientação à análise tomam-se, aqui, por referência, cinco aspectos centrais (MILLS, 1996; RUMMLER; BRACHE, 1994 ), a saber:

a - aumento do grau de participação dos trabalhadores no processo de elaboração e organização do próprio trabalho;

b - aumento no grau de autonomia das esferas hierarquicamente inferiores;

c- diminuição dos níveis hierárquicos;

d- implantação de instrumentos de medida para avaliação do processo e do produto do trabalho,

e- adoção de sistemáticas grupais de trabalho

Tentemos, ainda que limitadamente, dada a intenção deste trabalho, delinear os sentidos atribuídos a cada um deles pelo campo da gestão empresarial.

\section{a- Incremento à participação:}

Mesmo não incorporando alterações na base técnica, propostas inovadoras de gestão empresarial apontam e defendem a necessidade do aumento no grau de participação dos trabalhadores em todo o processo de trabalho.

Para efeito deste trabalho, o uso do conceito de participação, na esfera da empresa privada, pressupõe o conjunto dos diferentes e desiguais níveis de intervenção nos processos decisórios. Estes vão do simples acesso à informação de decisões que serão tomadas pela direção até a participação, via representação ou constituição de comitês, nos diferentes níveis decisórios que dada organização venha a possuir. Não é o caso de, neste momento, nos reportarmos aos debates acerca dos limites desse conceito e de suas consequências para a auto-organização dos trabalhadores. No entanto, chamamos a atenção para o retorno da participação como mecanismo para a melhoria da gestão empresarial que assola as produções críticas e não críticas a respeito dos novos processos de organização e gerência do trabalho.

Os estímulos ao chamado participacionismo têm encontrado defensores desde, pelo menos, a década de 1920, com a disseminação dos postulados da chamada Escola de Relações Humanas (MOTTA, 1997).

Nessa perspectiva participacionista, a literatura voltada para a formação e capacitação dos escalões de gerência defende que o incentivo à participação aprimora o desempenho e a competitividade das organizações, uma vez que incorpora a iniciativa dos trabalhadores e favorece a implementação de estratégias motivacionais para o desempenho do trabalho (MAXIMIANO, 1995). Vale lembrar que tais incentivos à participação resultam também de pressões desenvolvidas pelos próprios trabalhadores (MILLS, 1996).

\section{$b$ - Incremento à autonomia}

Educação: Teoria e Prática/ Rio Claro/ Vol. 25, n.50/ p. 435-452/ Set.-Dez. 2015. 
Em Maximiano (1995, p.72) autonomia é entendida como a "capacidade ou possibilidade de exercitar a iniciativa". Na concepção do autor, equipes autogerenciadas possibilitam a desespecialização de seus integrantes que, por passarem a realizar várias tarefas, garantem a adequação necessária às atuais demandas das organizações pela multifuncionalidade de papéis.

A proclamada autonomia vincula-se, ainda, ao "enriquecimento das tarefas" e à possibilidade dos trabalhadores e/ou equipes revestirem-se de empowerment, ou seja, da capacidade para definir a utilização dos meios mais adequados e, consequentemente, resolverem possíveis obstáculos para o alcance das metas estabelecidas, ainda que pelos níveis gerenciais: "O gerente deve fixar metas e investir indivíduos e equipes de 'empowerment', incluindo a utilização dos recursos destinados, não mais supervisionando a tarefa, mas avaliando os resultados" (MILLS, 1996, p.32).

A autonomia restringe-se às decisões no plano da execução, ou melhor, à escolha sobre como operacionalizar os meios disponíveis para o alcance de objetivos e metas gerais, centralmente definidos.

Pesquisa desenvolvida por Jean Lojkine, junto à empresa Renoult-Billancourt, sobre Grupos de Expressão Direta (GED), semelhantes aos Círculos de Controle de Qualidade,CCQs, conclui que a integração de "novas práticas gerenciais num sistema sempre dominado pelos critérios da rentabilidade, de retorno do investimento e de cash flow $^{1}$ conduz a [idênticos] processos de marginalização e de crise organizacional" (LOJKINE, 1995 , p.167). c- Diminuição dos níveis hierárquicos

Conhecido, também, como downsizing ou enxugamento, a diminuição dos níveis hierárquicos, no interior das organizações, está diretamente vinculada à necessidade destas se adequarem aos novos critérios de competitividade e produtividade.

Para alguns de seus proponentes, a eficiência das estruturas hierarquicamente concebidas, pautadas em modelos desenvolvidos sob os pressupostos de Taylor e Ford é apenas aparente, dado que o custo da manutenção de especialistas e dirigentes em larga escala, para planejamento e controle de processos, mostra-se desvantajoso com as novas tecnologias de informação. Segundo Mills (1996) deve-se buscar o alcance dos objetivos primários "redução de custos, melhoria da qualidade e aumento da capacidade de resposta" e não "perder tempo com objetivos secundários, como obedecer às ordens de um chefe" (MILLS, 1996, p.112).

Articulam-se a isso as possibilidades de planejamento e controle adquiridas com a introdução de tecnologias na estrutura organizacional — organização virtual — aliando-se tanto à diminuição espacial das unidades produtivas, quanto ao número de trabalhadores necessários à manutenção de sua estrutura.

Para Peter F. Drucker

[...] cortar pessoal, para cortar custos, é colocar os carros na frente dos bois. A única forma de se trazer os custos para baixo é reestruturando o trabalho. Isso irá, então resultar na redução de pessoas necessárias à execução do trabalho, e de forma muito mais drástica que aquela que seria conseguida pelos cortes mais radicais de pessoal (DRUCKER, 1996, p.129).

\footnotetext{
${ }^{1}$ Flutuação financeira.

Educação: Teoria e Prática/ Rio Claro/ Vol. 25, n.50/ p. 435-452/ Set.-Dez. 2015.
} 


\section{d-Instrumentos de medição e avaliação}

Com relação aos investimentos em sistemáticas de avaliação, observa-se uma intensificação da defesa da medição como instrumento para o aumento da competitividade e produtividade.

Pautadas na preocupação com a busca do defeito zero, implementadas nas organizações japonesas, as técnicas de avaliação centram-se menos nos resultados e mais nos processos, possibilitando, caso necessário, uma correção mais rápida e eficaz. Segundo Schonberger (1987), a fiscalização da qualidade durante todos os processos demandaria do setor de controle um número de ficais equivalente ao de trabalhadores em envolvidos, razão pela qual, segundo o autor, a maneira mais efetiva de controlar a qualidade do processo produtivo é a desenvolvida diretamente pelo próprio trabalhador.

A medição, fator desde sempre articulado à melhoria do desempenho, também é reforçada, seja pela adoção de sistemáticas descentralizadas de controle - modelo japonês seja pelo uso de modelos estatísticos e procedimentos tecnológicos mais sofisticados e abrangentes.

\section{$e$ - Trabalho em equipe}

O trabalho em equipe, como estratégia organizacional, pauta-se na possibilidade de o grupo servir como elemento para a melhoria de desempenho. Constitui-se numa forma de motivar as pessoas a internalizarem os objetivos do negócio (MILLS, 1996).

Na perspectiva da constituição de novas sistemáticas de disciplinamento da classe trabalhadora, tais proposições podem ser analisadas a partir da observação de Bruno (1996, p.96), para quem, "estamos transitando de um sistema repressivo, baseado no acatamento a uma ordem e na obediência a um chefe, para um sistema impessoal, baseado na internalização do regulamento e na adesão a uma lógica”. Tal lógica corresponde a do aumento da competitividade e da produtividade da organização, mediante a descentralização das decisões e as consequentes descentralização e introjeção das responsabilidades.

A possibilidade de constituição de equipes de trabalho articula-se tanto à introdução de mudanças na base técnica do trabalho, no caso de trabalhadores diretamente envolvidos na esfera da produção, quanto à adoção de medidas de enxugamento dos setores hierárquicos.

Para Jacob Gorender (1997, p.319), se o trabalho em equipe oferece, por um lado, estímulo ao trabalhador, por outro, submete-o ao controle do grupo, eliminando custos com a supervisão: "Os indivíduos, que a compõem, ficam incessantemente submetidos à vigilância coletiva, dado que as falhas individuais se refletem no resultado do trabalho conjunto".

\section{A gestão empresarial estendida à escola pública: um exercício de reflexão}

Se, no caso das unidades produtivas, a generalização de alterações nos padrões organizacionais é tendência que se materializa de forma desigual, no caso da escola pública e, mais especificamente das redes públicas de ensino do Brasil, a tendência parece constituir-se, 
que nos permite voltar o olhar às grandes redes de ensino nas quais ocorrem profundas reformas, como é o caso da rede estadual de ensino de São Paulo. (ADRIÃO, 2006)

As reformas nas grandes redes públicas, às quais nos referimos, apresentam características que, se não podem ser apreendidas de maneira homogênea, nos permitem considerar certas tendências dentre as quais se encontra a adoção de padrões privados de gestão e o recurso ao setor privado como orientador (e, às vezes, implementador) de políticas e programas envolvendo a gestão da escola.

O elemento novo da perspectiva apresentada reside menos na tentativa de implantar a racionalidade capitalista na gestão da escola pública, fenômeno já observado por Felix (1984), Paro (1988), Bruno (1996) quando da tentativa de adoção dos parâmetros tecnicistas de administração escolar, principalmente a partir do final dos anos 1960 e 1970, e mais nas alterações nos meios para o alcance dessa racionalidade.

Neste artigo refletimos sobre aproximação das orientações de reforma da gestão da escola pública à da lógica empresarial, iniciadas nos anos 1990 (OLIVEIRA, 1997; ADRIÃO, 2006, dentre outros).

Um quadro síntese (Quadro 1) de efeito comparativo, pode facilitar a percepção de similitudes e diferenças entre os pressupostos dos modelos gerenciais, mais flexíveis, adotados por setores mais avançados da iniciativa privada, e aqueles adotados por sistemas públicos de ensino, na tentativa de referendar a hipótese inicial acerca da semelhança de métodos e técnicas, como instrumento para a alteração nos padrões de gestão.

Quadro 1 - Síntese dos procedimentos de flexibilização dos padrões de gestão

\begin{tabular}{|l|l|}
\hline \multicolumn{1}{|c|}{ Empresa } & \multicolumn{1}{c|}{ Escola } \\
\hline $\begin{array}{l}\text { Incentivo à participação, no local de } \\
\text { trabalho, dos trabalhadores na solução de } \\
\text { problemas operacionais. }\end{array}$ & $\begin{array}{l}\text { Estímulo à participação dos diversos } \\
\text { segmentos da comunidade escolar } \\
\text { (trabalhadores e usuários da escola) na } \\
\text { resolução de problemas operacionais. }\end{array}$ \\
\hline $\begin{array}{l}\text { Aumento da autonomia das esferas } \\
\text { hierarquicamente inferiores. }\end{array}$ & $\begin{array}{l}\text { Aumento da autonomia administrativa, } \\
\text { pedagógica e financeira. }\end{array}$ \\
\hline $\begin{array}{l}\text { Implantação de instrumentos externos de } \\
\text { medida e avaliação de processos e produto. } \\
\text { Avaliação do produto por parte dos } \\
\text { usuários/clientes. }\end{array}$ & $\begin{array}{l}\text { Criação de mecanismos externos para } \\
\text { avaliação de desempenho institucional, via } \\
\text { desempenho de alunos. } \\
\text { Qualificação da demanda para avaliação do } \\
\text { serviço educacional. }\end{array}$ \\
\hline Diminuição de níveis hierárquicos. & $\begin{array}{l}\text { Descentralização e desconcentração } \\
\text { administrativa com eliminação de esferas } \\
\text { governamentais intermediárias de gestão. }\end{array}$ \\
\hline Adoção do trabalho em equipe. & $\begin{array}{l}\text { Redefinição dos espaços coletivos de } \\
\text { trabalho docente }\end{array}$ \\
\hline
\end{tabular}

Fonte: Elaborado pelas autoras

Educação: Teoria e Prática/ Rio Claro/ Vol. 25, n.50/ p. 435-452/ Set.-Dez. 2015. 
A intenção do quadro é ilustrar, ainda que esquematicamente, semelhanças entre tendências na organização da gestão e do trabalho na empresa e na escola pública. Trata-se de esforço de construção de um esquema analítico que visa possibilitar a compreensão e síntese de procedimentos, não existindo em estado puro na realidade.

A primeira comparação diz respeito ao incentivo à participação. Seja no caso das unidades escolares, seja no caso das empresas, a amplitude e abrangência da participação dos trabalhadores e usuários remete, de um lado, à capacidade de organização e pressão dos segmentos em questão, e, de outro à permeabilidade das organizações a tais reivindicações. Em outras palavras, resulta da correlação de forças entre os segmentos em disputa: proprietários e trabalhadores no caso das empresas, educadores/usuários e gestores do sistema educacional - se o foco for o sistema - e educadores e usuários quando focamos a unidade escolar.

Ainda cabe ressaltar que, no caso das empresas, os processos participativos podem levar à cooptação dos trabalhadores, diminuindo conflitos, além de se mostrarem um instrumento para o aumento da produtividade, como vimos anteriormente (MOTTA, 1997; HELOANI, 1994). No que diz respeito à escola, ainda que haja a possibilidade de cooptação, especialmente por parte de gestores em escolas e nos sistemas (MENDONÇA, 2000; PERONI; ADRIÃO, 2007), as alterações nas formas de participação vinculam-se à alteração no sentido atribuído à participação e democratização da unidade escolar.

O segundo ponto, introduzido para efeito de comparação, refere-se ao aumento da autonomia das esferas inferiores frente à hierarquia. $\mathrm{O}$ aumento da autonomia, no interior dos programas que propõem a alteração nos padrões de gestão, articula-se ao aumento da eficiência - menor custo para um máximo de benefícios - das organizações.

O aumento da eficiência relaciona-se, em ambos os casos, à possibilidade da unidadefim responder e resolver, com a maior rapidez possível, problemas surgidos na unidade. Nesse sentido, algumas empresas implantam grupos autônomos (ilhas ou células) de produção com o objetivo de, rompendo com a linha de produção, responsabilizar um dado grupo pela execução, senão total, ao menos parcial de um dado bem ou peça. Dessa forma, o grupo pode introduzir alterações na execução de suas tarefas, desde que estas impliquem o aumento da 
produtividade de seu trabalho. ${ }^{2}$ Logo, do ponto de vista das organizações privadas, a autonomia restringe-se, e muito, à esfera da execução, ainda que se mantenha a prática do trabalho prescrito.

No caso das unidades escolares, a proposta de autonomia também se limita à esfera da execução do trabalho pedagógico e à gestão de recursos descentralizados. Aprofunda-se a prescrição do trabalho docente e de gestores por meio da tendência a se implementar um currículo prescrito, seja pelo setor privado, do que são exemplos os sistemas apostilados de ensino (ADRIÃO et al, 2009; GARCIA et al, 2012), ou por orientações advindas do gestor público.

No que diz respeito à escola, essa lógica procura romper com uma tradição da cultura escolar relacionada à possibilidade de o professor - na pior das hipóteses, individualmente elaborar e implementar o seu projeto pedagógico. Tal cultura se manifesta na expressão: $d a$ porta da sala de aula para dentro faço o que quero, - ainda que de conteúdo altamente autoritário se se pensar numa relação dialógica entre professor-aluno e na existência de práticas docentes que ampliam e reforçam a exclusão - significava, também, a preservação do trabalho docente frente às ingerências tanto das equipes técnicas das escolas, quanto do experimentalismo e/ou autoritarismo de muitas políticas governamentais. Nesse sentido, o controle do trabalho do professor, nos moldes do que ocorria na empresa capitalista e do que se anuncia para a escola pública, de fato não se verificava.

A ampliação do controle sobre o trabalho, a que nos referimos, é viabilizada por diferentes mecanismos e instrumentos de avaliação externa: em São Paulo é exemplar o Sistema de Avaliação de Rendimento do Estado de São Paulo - SARESP. Criado em meados da década de 1990, o SARESP tomou proporções relevantes na organização do trabalho escolar da rede na década seguinte, atingindo a organização curricular.

Registra-se que, atualmente, a rede estadual paulista, uma das pioneiras em avaliações de larga escala, é apenas mais uma dentre as redes municipais e estaduais do país a adotarem o mecanismo, além do Sistema de Avaliação da Educação Básica, SAEB, de responsabilidade do Ministério da Educação e de caráter nacional.

Em que pesem as diferenças entre os sistemas de avaliação mencionados, encontramos o terceiro item da comparação. Com eles, o desempenho da escola e do trabalho docente é

\footnotetext{
${ }^{2}$ As pesquisas na área da sociologia do trabalho acompanharam de perto essas tentativas, dentre as quais podemos citar: Hirata e Zafirian (1991); Salerno (1992, 1994); Zarifian e Veltz (1993) e Zarifian (1990, 1994), além dos trabalhos e autores citados no corpo do trabalho.

Educação: Teoria e Prática/ Rio Claro/ Vol. 25, n.50/ p. 435-452/ Set.-Dez. 2015.
} 
monitorado e avaliado em função de padrões, generalizados e pré-definidos, para o produto do trabalho escolar: quantidade, tipo de informação e habilidades desenvolvidas junto aos alunos em cada ano/nível de escolarização.

As potencialidades que têm as avaliações em larga escala de funcionarem como mecanismo de gestão e controle são bastante bem analisadas por diferentes pesquisadores, dentre os quais Freitas (2004, 2005a, 2005b); Sousa (2011, 2014); Sousa e Oliveira (2003); Bonamino e Sousa (2012), Bertagna (2010); Bertagna e Borghi (2011).

Estudos desenvolvidos pelo Grupo de Estudos e Pesquisas em Política Educacional, GREPPE, por sua vez, indicaram que empresas privadas com fins lucrativos se valem dos resultados de avaliações externas para comercializar seus produtos em redes públicas, com promessas de elevação nos resultados e índices, assim como segmentos do empresariado, organizados em entidades sem fins lucrativos, oferecem planos e estratégias de gestão com os mesmos objetivos (ADRIÃO et al. 2009).

Ainda com respeito às sistemáticas de avaliação e controle, outra semelhança pode ser percebida: a adoção das novas tecnologias informacionais. A introdução de instrumentos de armazenamento e tratamento da informação, por meio de redes computadorizadas, possibilita o mapeamento e o monitoramento de processos e produtos. Do ponto de vista da educação, isso permite a agregação e a consolidação de dados quantitativos que, certamente, representam um avanço para a caracterização dos quadros de atendimento da educação nacional.

A questão é que as mesmas tecnologias estão sendo utilizadas para aferição do desempenho da escola, ou da sua qualidade. Aqui, como na organização capitalista do trabalho, parece que os novos padrões de gestão insistem em implementar a divisão técnica do trabalho ao separarem os que executam dos que elaboram, na medida em que definem o que deva ser o produto da escola, e implantam modelos para aferição desse produto.

Cita-se, como exemplo de setor privado que desenvolve diferentes recursos tecnológicos para monitoramento do trabalho docente, o instrumental produzido pelo Instituto Ayrton Senna (IAS) para as escolas públicas, denominado, originalmente, Sistema Instituto Ayrton Senna de Informação, SIASI.

O SIASI permite que o gestor local, quando a rede se torna parceira do IAS e implanta seus programas, tenha informações sobre as rotinas das unidades escolares no que se refere ao andamento dos trabalhos em sala de aula, frequência de docentes e discentes, desempenho, dentre outros. Os dados de cada uma das redes de ensino parceiras são alocados em banco de Educação: Teoria e Prática/ Rio Claro/ Vol. 25, n.50/ p. 435-452/ Set.-Dez. 2015. 
acesso aos técnicos responsáveis pelas parcerias no âmbito do Instituto, que os controla e monitora (ADRIÃO; PERONI, 2013; PERONI, 2012).

Cabe ressaltar, ainda, que, entre as intenções do controle via avaliação externa e a sua operacionalização nas e pelas escolas há um longo caminho que pode contar, inclusive, com resistências e formas, forjadas na escola, que, driblando sua aplicação, comprometam os resultados esperados. Parece que as escolas criam e recriam mecanismos de resistência a controles centralizados (LIMA, 1997, 2001). Apesar dessas resistências é necessário registrar que a associação entre avaliações estandardizadas e políticas de bonificação tende a promover maior controle sobre o trabalho (HYPOLITO, 2011).

O outro mecanismo de avaliação da qualidade do produto, utilizado pelas empresas privadas, consiste na generalização, principalmente a partir da adoção das normas de qualidade estabelecidas pela International Organization for Standardization (ISO) e da Gerência de Qualidade Total, da escuta aos reclamos do cliente ou o foco no cliente. Assim, clientes internos (membros das diferentes repartições/equipes/departamentos da empresa ou de fornecedores) ou externos (compradores dos bens ou serviços) devem ser fontes de informações a respeito do desempenho e da qualidade do serviço e/ou bem prestado e/ou adquirido. Para tanto, os clientes devem possuir informações a respeito dos processos e do produto, as quais são fornecidas pela própria empresa ou pelo setor, uma vez que estes não necessariamente as possuem ou, no caso dos clientes externos, sequer precisariam possuir. (ADRIÃO, 2006).

De maneira, digamos, análoga à ideia de qualificação da demanda, que sustenta a utilização e a divulgação dos resultados obtidos pela escola junto à população usuária, parece recorrer à mesma lógica: o usuário da escola pública não sabe o resultado que dela deve esperar e, por isso, o acesso aos resultados da escola que utiliza lhe permitiria pressionar para que o desempenho melhore.

Outro exemplo importante de participação sob a ótica da relação de consumo, diz respeito à divulgação dos resultados de avaliações externas ${ }^{3}$.

Embora não se tenha, ainda, adotado no país, oficialmente, a política do ranqueamento público das escolas a partir dos índices nacionais, este já ocorre capitaneado pela imprensa que, regularmente, publica listagens com melhores e piores escolas no âmbito nacional ou

\footnotetext{
${ }^{3}$ No Distrito Federal, desde 2013, há legislação que obriga as escolas públicas e privadas divulgarem em local público os resultados do IDEB anual (Lei Distrital $N^{\circ} 5.128$, de 04 de julho de 2013). No Rio de Janeiro, a divulgação foi tornada obrigatória em 2011 (Decreto n. ${ }^{\circ} 34121$, de 13 de julho de 2011).

Educação: Teoria e Prática/ Rio Claro/ Vol. 25, n.50/ p. 435-452/ Set.-Dez. 2015.
} 
local, a partir dos resultados dos sistemas de avaliação. Empresas privadas que comercializam produtos destinados ao ensino público, como os sistemas privados de ensino, também dispõem, em suas cartelas de produtos, de instrumentos de avaliação e ranqueamento (tal perspectiva encontra-se analisada em ADRIÃO et al., 2009; ADRIÃO, et al, 2012).

Diferentemente da ideia de participação na construção coletiva do projeto pedagógico da sua escola, ou seja, da ideia de inclusão dos usuários na definição dos rumos dessa escola e, portanto, da avaliação de seus resultados por meio de um acompanhamento dos processos, a posição que lhes é reservada, como clientes de qualquer serviço, é a de avaliadores externos do serviço adquirido, a partir de padrões que não construíram.

Por pressuposto, a participação é restrita a uma hipotética capacidade de o usuário avaliar a qualidade da escola, incidindo sobre ela ou, aparentemente o mais esperado, realizando opções mais qualificadas (ADRIÃO, 2006; ADRIÃO; GARCIA, 2008)

O quarto item que compõe o quadro comparativo diz respeito à diminuição dos níveis hierárquicos observados nas medidas de enxugamento, tanto na esfera das empresas como na do Estado em geral, e dos sistemas educacionais em particular.

No último caso, as medidas incluem desde a extinção de órgãos intermediários das estruturas das Secretarias, com a consequente redistribuição das atribuições para os órgãos inferiores remanescentes do sistema - no caso da rede do Estado de São Paulo podemos exemplificar com a extinção das Divisões Regionais de Ensino e a descentralização e desconcentração de suas antigas atribuições para as Delegacias de Ensino, como veremos mais adiante - até a substituição de algumas de suas funções por meio da terceirização.

Aqui, como na esfera empresarial, a lógica adotada é a da diminuição do tamanho da estrutura e, portanto, dos encargos e custos de manutenção, pela contratação de grupos privados para a execução de tarefas determinadas: efetuada a tarefa o contrato é concluído.

Por último, cabe comentar a adoção do trabalho em equipe ou em grupo. Aparentemente, as formas são semelhantes: no caso das empresas, o trabalho em equipe ou grupo está diretamente relacionado à reorganização do trabalho e à aparente possibilidade de seu planejamento e avaliação, e, no caso das unidades escolares, à introdução de horários coletivos de trabalho, como parte integrante da jornada docente, relaciona-se também às atividades de planejamento e avaliação contínua de sua prática. No entanto, a diferença parece incidir no grau de autonomia que os grupos possuem para implementar as alternativas sugeridas, uma vez que na empresa privada, estes estão sujeitos à autorização da gerência, e nas unidades escolares, sobretudo nas redes públicas de ensino, inclusive por previsão Educação: Teoria e Prática/ Rio Claro/ Vol. 25, n.50/ p. 435-452/ Set.-Dez. 2015. 
normativa, há, formalmente, possibilidades de que as decisões tomadas pelos próprios docentes. Porém, cada vez mais se generalizam políticas e programas que minimizam essas possibilidades, a exemplo da adoção de sistemas privados de ensino.(ADRIÃO et al. 2009; ADRIÃO, et al, 2012; GARCIA et al. 2012)

\section{Considerações finais}

Inicia-se este último tópico considerando que certo tipo de autonomia, nos dois casos (empresa e escola), limita-se à escolha dos melhores meios para se atingir resultados centralmente definidos. Isto sabemos todos, influi na organização e na gestão do trabalho, justamente porque a escolha dos meios não está dissociada dos fins esperados. Ao que parece, os defensores dessas sistemáticas tendem a ignorar a diversidade e a desigualdade que caracteriza a oferta da educação básica, inclusive por conta da diversidade existente entre os grupos de usuários de uma e outra escola. Em nome de uma suposta busca de eficiência da escola pública, ignoram-se as características fundamentais do processo de trabalho pedagógico.

Se a lógica da gestão privada se articula, no caso da introdução dos novos padrões de gestão, como na empresa, ao aumento da produtividade e da eficiência da escola, o tratamento dado a essa percepção pode, ao menos tendencialmente, assumir três enfoques.

No primeiro, podemos rechaçar os mecanismos de ampliação da autonomia na gestão das escolas, via mecanismos de descentralização, desconcentração e reorganização do trabalho, por associá-los indiretamente à adoção de paradigmas privados. Nesse caso, perguntamo-nos sobre a validade e o conteúdo das lutas que se desenvolveram pela incorporação de parte desses instrumentos como mecanismos de democratização da escola e de superação de sua estrutura hierárquica.

O segundo enfoque, de caráter mais pragmático, centra sua posição a partir de indicativos mensuráveis de melhoria dos serviços prestados pela escola. Nesse caso, é certo que, via de regra, o ensino destinado aos filhos da classe trabalhadora tem sido de baixo nível, excludente e seletivo. Como resposta a tal caracterização, os atuais gestores centram suas propostas em instrumentos de correção intraescolares, buscando maximizar resultados com a diminuição de custos e implicando, como vimos, numa possível reorganização do trabalho escolar.

O risco dessa abordagem consiste, justamente, na simplificação dos fatores condicionantes do desempenho da escola. É certo que a escola, por razões que remontam de um lado à própria natureza da sociedade e, de outro, a lógicas internamente desenvolvidas, constrói instrumentos para o fracasso ${ }^{4}$. No entanto, desconfiando da neutralidade dos meios, perguntamo-nos sobre a possibilidade do uso de mecanismos forjados na esfera da exploração do trabalho, para a alteração desse estado de coisas.

Em perspectiva antagônica ao recurso a mecanismos próprios à exploração do trabalho, temos a considerar a concepção de administração que orienta as preocupações com a

\footnotetext{
${ }^{4}$ Ver, entre outros, Patto (1990) e Arroyo ( 1992).

Educação: Teoria e Prática/ Rio Claro/ Vol. 25, n.50/ p. 435-452/ Set.-Dez. 2015.
} 
qualidade da escola pública. Trabalhos como os de Vitor Paro alertavam, em meados da década de 1980, para a necessidade de se ter atenção à especificidade da natureza do trabalho pedagógico e, por conseguinte, à inviabilidade, inclusive por esta razão, da adoção dos pressupostos da administração capitalista na gestão da escola pública, sob pena e risco de descaracterizar o próprio trabalho pedagógico. Além disso, enfatizava a relevância da participação dos usuários na gestão da escola, dada a necessidade de a mesma voltar-se para os interesses da população que serve (PARO, 1988).

Conclui-se este artigo, reiterando que a compreensão sobre a especificidade do processo de trabalho pedagógico e, portanto, da profunda inadequação de transposições dos modelos empresariais à educação escolar é de fundamental importância na construção de ferramentas com vistas à qualificação da educação pública.

\section{Referências}

ADRIÃO, T. Educação e produtividade: a reforma do ensino paulista e a desobrigação do Estado. São Paulo: Xamã, 2006.

ADRIÃ̃, T. Indicações e Reflexões sobre as Relações entre Esferas Públicas e Privadas para a Oferta Educacional no Brasil. Políticas Educativas, Porto Alegre, v. 3, n. 1, p.48-64 . 2009. Disponível em: <http://seer.ufrgs.br/index. php/Poled/article/view/22531/13064>. Acesso em: 15 fev. 2015.

Políticas Educativas, Porto Alegre, v. 3, n.1, p.48-64, 2009.

ADRIÃO, T. et. al. Uma modalidade peculiar de privatização da educação pública: a aquisição de 'sistemas de ensino' por municípios paulistas. Educação \& Sociedade, (Impresso), v. 30, n,108 p.799-818, outubro, 2009.

ADRIÃO, T., et al. . As parcerias entre prefeituras paulistas e o setor privado na política educacional: expressão de simbiose?.. Educação \& Sociedade (Impresso), v. 33, no. 119, p. 533-549, abril/ junho, 2012.

ADRIÃO, T.; BEZERRA, E. P. O setor não lucrativo na gestão da educação pública: corresponsabilidade ou debilidade. Currículo sem Fronteiras, , v. 13, n.2, p. 256268,mai/ago. 2013.

ADRIAO, T.; GARCIA, T. Oferta Educativa e responsabilização no PDE: análise do Plano de Ações Articuladas. Cadernos de Pesquisa, v. 38, n.135, p.779-796, 2008.

ADRIÃO, T. Escolas charters nos EU: contradições de uma tendência proposta para o brasil e suas implicações para a oferta da educação pública. Educação e Filosofia, v 28, n.1, p. 263-281 Disponível em http://www.seer.ufu.br/index.php/EducacaoFilosofia/article/view/24613. Acesso em $15 / \mathrm{fev} / 2015$. 
ADRIÃO, T. GARCIA, T. Gestão privada da educação pública: um olhar sobre o modelo de 'charters school' nos EUA e sua aproximação para a realidade e brasileira. Fapesp.2014. (Relatório de pesquisa).

ADRIÃO, T. PERONI, V. Consequências da atuação do instituto Ayrton Senna para a gestão da educação pública: observações sobre 10 estudos de caso. Práxis Educativa, Ponta Grossa, v.6, n.1, p. 45-53, Jan./Jun. 2011. Disponível em: <file:///C:/Users/theresa/Downloads/25227326-1-PB.pdf>. Acesso em: 15 fev. 2015.

ADRIÃO, T.; PERONI, V (Orgs). Gestão Municipal da Educação e as Parcerias com o Instituto Ayrton Senna. Recife: FUNAPE, 2013.

ARROYO, M. Fracasso-sucesso: o peso da cultura escolar e do ordenamento da educação básica. Em Aberto, Brasília, Ano 11, n.53, p.46-53, Jan./Mar. 1992.

BALL, S. Diretrizes globais e políticas locais em educação. Currículo sem Fronteiras, v.1, n.2, p. 99-116, Jul./Dez. 2001.

BARROSO, J. O estudo da autonomia da escola: da autonomia decretada à autonomia construída. In: O estudo da Escola. Porto: Porto Ed., 1996.

BARROSO, J. O Estado, a educação e a regulação das políticas públicas. Educ. Soc., Campinas, v. 26, n. 92 - Especial, p. 725-751, Out. 2005.

BERTAGNA, R. H. Avaliação e progressão continuada: o que a realidade desvela. PróPosições, Campinas, v. 21, no 3 (63), , p. 193-218-218, set./dez,2010.

BERTAGNA, R. H.; BORGHI, R. F. Possíveis relações entre avaliação e sistemas apostilados privados em escolas públicas. Educação Teor. \& Prat., Rio Claro, v. 21, no, 38, .p. 132-, 146, 2011. Disponível em.

http://www.periodicos.rc.biblioteca.unesp.br/index.php/educacao/article/view/5269 . Acesso em 21 de julho de 2015.

BONAMINO, A.; SOUSA, S. Z. Três gerações de avaliação da educação básica no Brasil: interfaces com o currículo da/na escola. Educação \& Pesquisa, São Paulo, v. 38, n.2, p. 373 388, abr/jun. 2012.

BRUNO, L. Educação, qualificação e desenvolvimento econômico. In:

(Orgs.) Educação e desenvolvimento econômico. São Paulo: Atlas, 1996. p.91-123.

BRUNO, L. Poder e Administração no Capitalismo Contemporâneo. In: OLIVEIRA D. A.

(Org.). Gestão Democrática da Escola. Petrópolis: Vozes, 1997. p. 7-31.

DISTRITO FEDERAL. Lei Distrital 5.128, de 04 de julho de 2013. Dispõe sobre a divulgação do Índice de Desenvolvimento da Educação Básica - IDEB nos estabelecimentos públicos e particulares de ensino do Distrito Federal. Brasília: Portal SinTSE, 2013.

Disponível em: <http://sintse.tse.jus.br/documentos/2013/Jul/8/lei-no-5-128-de-4-de-julho-de2013-dispoe-sobre-a>. Acesso em: 14 dez. 2015. 
DRUCKER, P. F. Administrando para o futuro: os anos 90 e a virada do século. 5 ed. São Paulo: Pioneira, 1996.

FELIX, M. de F. Costa. Administração escolar: Um problema educativo ou empresarial. São Paulo: Cortez/Autores Associados, 1984.

Freitas, L.C . A avaliação e as reformas dos anos de 1990: novas formas de exclusão, velhas formas de subordinação. Educação e Sociedade, Campinas, v. 25, n.86, p. 133-170, 2004.

FREITAS, L. C. Eliminação adiada: novas formas de exclusão introduzidas pelas reformas. Pro-Posições, Campinas, v. 16, n.48, p. 111-144,. 2005a.

FREITAS, L,C . Qualidade negociada: avaliação e contrarregulação na escola pública. Educação \& Sociedade, Campinas, v. 26, n.92, p. 911-933. 2005 b.

FREITAS, L.C. Os reformadores empresariais da educação: da desmoralização do magistério à destruição do sistema público de educação. Educação \& Sociedade, Campinas, v. 33, no. 119 , p. 379-404. 2012

GARCIA, T. et al. As parcerias público-privado para a compra de sistemas de ensino: análise das consequências para a organização do trabalho na escola. CNPq. 2012. (Relatório de pesquisa).

GORENDER, J. Globalização, Tecnologias e Relações de Trabalho. Estud. Av., São Paulo, v. 11 n. 29, p. 311-361, Jan./Abr. 1997. Disponível em:

<http://www.scielo.br/scielo.php?pid=S0103-40141997000100017\&script=sci_arttext>. Acesso em: 10 jan. 2015.

GOUNET, T. Fordismo e Toyotismo. São Paulo: Boitempo, 1999.

HARVEY, D. A Condição Pós--moderna. 11 ed. São Paulo: Loyola, 2002.

HELOANI, J. R. M. Organização do Trabalho e Administração: uma visão multidisciplinar. São Paulo: Cortez, 1994.

HILL, D. O Neoliberalismo Global, a Resistência e a Deformação da Educação. Currículo sem Fronteiras, v.3, n.2, p. 24-59, Jul./Dez. 2003.

HIRATA, H. ; ZARIFIAN, P. Força e fragilidade do modelo japonês. Estudos Avançados, São Paulo, v. 5, n, 12, p. 173-185. 1991.

HYPOLITO, A. M. Processo de Trabalho na Escola: algumas categorias para análise. Teoria e Educação, Porto Alegre, v. 4, p. 3-21, 1991.

HYPOLITO, A.M. Reorganização Gerencialista da Escola e Trabalho Docente. Educação Teor. \& Prát. Rio Claro, v. 21, n.38 p. 59-78, . 2011. Disponível em: http://www.periodicos.rc.biblioteca.unesp.br/index.php/educacao/article/view/5265/4147.Ace sso em 19 de julho de 2015. 
LIMA, L. C.. O Paradigma da Educação Contábil: Políticas Educativas e Perspectivas Gerencialistas no Ensino Superior em Portugal. Políticas Públicas para a Educação Superior, p. 23 62. SGUISSARDI V. SILVA Jr. (Orgs). Piracicaba/São Paulo: UNIMEP, 1997.

LIMA, L.C. A escola como organização educativa: uma abordagem sociológica. São Paulo: Cortez, 2001.

LIMA, L. C. Políticas educacionais, organização escolar e trabalho dos Professores.

Educação Teor.\& Prát., Rio Claro, v, 21, no 38, p.8-26 . 2011.Disponível em: http://www.periodicos.rc.biblioteca.unesp.br/index.php/educacao/article/view/5262.Acesso em 27 de setembro de 2015

LOJKINE, J. A Revolução informacional. São Paulo: Cortez. 1995.

LÖWY, M. A teoria do desenvolvimento desigual e combinado. Rev. Instit. Est. Social., São Paulo, inserir v., n. 1, p. 73-80, out. 1998.

MAXIMIANO, A. C. A. Além da Hierarquia: como implantar estratégias participativas para administrar a empresa enxuta. São Paulo: Atlas, 1995.

MENDONÇA, E. A regra e o jogo: Democracia e patrimonialismo na educação brasileira. Campinas: Edições Lapplane/Unicamp, 2000.

MILLS, D. Q. Empowerment: um impacto, seis passos para se estabelecer uma organização de alto desempenho. Rio de Janeiro: Campus, 1996.

MOTTA, F.C.P. Teoria das Organizações: Evolução e Crítica. São Paulo: Pioneira, 1997.

OLIVEIRA, D. A. (Org.). Gestão democrática da educação: desafios contemporâneos. 3 ed. Petrópolis: Vozes, 1997.

OLIVEIRA, D. A. A privatização da gestão da educação pública na reforma do Estado brasileiro. Universidade \& Sociedade, Brasília, , Ano XII, n.28, p. 65-72, 2002.

OLIVEIRA, D. A. Política, Gestão e Financiamento da Educação e as novas formas de regulação. Teoria e Prática da Educação, Maringá, v. 7, n.3, p. 327-333. 2004,.

OLIVEIRA, D.A. A política educacional brasileira: Entre a eficiência e a inclusão democrática. Educação \& Filosofia, Uberlândia, v. 28, n. especial, p. 225-243, 2014. Disponível em: http://www.seer.ufu.br/index.php/EducacaoFilosofia/article/view/24611. Acesso em 14 de maio de 2015.

PARO, V.H. Administração Escolar: introdução crítica. 3 ed. São Paulo: Cortez, 1988.

PARO, V.H. Parem de preparar para o trabalho!!! Reflexões acerca dos efeitos do neoliberalismo sobre a gestão e o papel da escola básica. In: FERRETTI, C. J; REIS SILVA 
JR. J.R. OLIVEIRA. M.R.S. (Orgs.). Trabalho, formação e currículo: para onde vai a escola. São Paulo: Xamã, 1999. p. 101-120.

PARO, V.H. Trabalho docente na escola fundamental: questões candentes. Cadernos de Pesquisa São Paulo, , v. 42,.no 146 p. 586-611, .mai/ago, 2012.

PATTO, M.H.S. A produção do fracasso escolar: histórias de submissão e rebeldia. São Paulo: Casa do Psicólogo, 1990.

PERONI, V. M.V. A gestão democrática da educação em tempos de parceria entre o público e o privado. Pro-Posições, Campinas, v. 23, n. 2, p.19-31, Ago. 2012. Disponível em:

$<$ http://www.scielo.br/scielo.php?script=sci_arttext\&pid=S0103-

$73072012000200003 \& \operatorname{lng}=$ pt\&nrm=iso $>$. Acesso em: 06 jan. 2015.

PERONI, V.M.V. Redefinições no papel do Estado: parcerias público-privadas e a democratização da educação. Archivos Analíticos de Políticas Educativas/Education Policy Analysis Archives, Porto Alegre, v. 21, no 47, p. 1-20, mai., 2013.

PERONI, V, ADRIÃO, T. (Orgs.). PDDE. Uma proposta de redefinição do papel do Estado na educação? Brasília: INEP, 2007.

RIO DE JANEIRO [Município]. Decreto n. 34121, de 13 de julho de 2011. Dispõe sobre a obrigatoriedade de divulgação do Índice de Desenvolvimento da Educação Básica - IDEB, e/ou do Índice de Desenvolvimento da Educação do Município do Rio de Janeiro - IDERIO, nos estabelecimentos da Rede Pública Municipal de Ensino do Rio de Janeiro. Rio de Janeiro: Executivo municipal http://doweb.rio.rj.gov.br/visualizar_pdf.php?reload=ok\&edi_id=00000283\&page=10\&search $=$ decreto\%2034121. Acesso em 21 de julho de 2015.

RUMMLER, G. A., BRACHE, A.L. Melhores desempenhos das empresas. São Paulo. Makron Books, 1994.

SALERNO, M. S. Produção integrada e flexível e processo operatório: notas sobre sindicatos e a formação profissional. In: MACHADO, L. R. S. (Org.). Trabalho e educação. Campinas: Papirus, 1992. p. 87-94.

SALERNO, M, S. Mudança organizacional e trabalho direto em função de flexibilidade e performance da produção industrial. Produção, São Paulo, v. 4, n.1, p. 5-22.1994.

SCHONBERGER, R. J. Técnicas industriais japonesas: nove lições ocultas sobre a simplicidade. 2 ed. São Paulo: Pioneira, 1987.

SOUSA, S.M.Z.L. Avaliação e gestão da educação básica. In: DOURADO, L. F. (Org.). Políticas e gestão da educação no Brasil: novos marcos regulatórios. São Paulo: Xamã, 2011,p.31-45.

SOUSA, S.M.Z. L. Avaliação na escola básica: controvérsias e vicissitudes de significados. In: FERNANDES, C. de O. (Org.). Avaliação das aprendizagens: sua relação com o papel social da escola. São Paulo: Cortez, 2014,p.93-112.

Educação: Teoria e Prática/ Rio Claro/ Vol. 25, n.50/ p. 435-452/ Set.-Dez. 2015. 
SOUSA, S. M. Z. L.; OLIVEIRA, R. P. Políticas de avaliação da educação e quase mercado no Brasil. Educação \& Sociedade, Campinas, v. 24, n.84, p. 873-895, set.. 2003.

TROTSKY, L. História da revolução russa. 2 ed. Rio de Janeiro: Paz e Terra, 1977.

ZARIFIAN, P. As novas abordagens da produtividade. In: SOARES, R. (Org.). Gestão da empresa: automação e competitividade. Brasília: IPEA, 1990. p. 73-97.

ZARIFIAN, P.. Compétences et organization qualifiante en milieu industriel In: MINET, F. et al. (Org). La Compétence: mythe, construction ou réalité? Paris: L’ Harmattan, 1994. p.1.11.133.

ZARIFIAN, P.; VELTZ, P. Verrs de nouveaux modèles d'organisation?. Sociologie du Travail, Paris, v. 25, n. 1, p.3-25,. 1993.

Recebido em: 21/07/2014

Aprovado para publicação em: 09/11/2015

Publicado em: 22/12/2015 